\title{
The process accuracy of reconstruction of cutting edges geometry in the optical measuring systems
}

\author{
Dokładność procesu odtwarzania geometrii ostrzy skrawających \\ w optycznych systemach pomiarowych
}

\author{
JAN BUREK \\ BARBARA JAMUŁA *
}

The comparative analysis of two different optical measuring systems enabling the reconstruction of the cutting edges geometry is presented. For research uses: focus-variation microscope Alicona G4 and professional 3D scanner Zeiss Comet LヨD 2.

KEYWORDS: optical measurements, cutting tools, measurement accuracy

Optical measurements offer much greater flexibility than contact measurements and allow the collection and processing of large sets of points within a few seconds during one measurement [4]. Depending on the size of the element being analyzed, the optical devices are intended for measurements on a micro or macro scale and describe the object by measuring the coordinates of points [5]. They are based on image analysis [3,6], and the key advantage of such systems is the speed of measurement. Therefore, leading manufacturers of cutting tools are increasingly using non-contact measuring devices.

Geometry measurement of the cutting tool with the use of optical systems is possible due to the use - depending on the type of measuring device - of special methods [1]. Three-dimensional measurement allows you to verify the cutting properties of the tool depending on its condition and wear. The main elements of the analysis are cutting edge geometries that have a significant impact on the cutting process, the quality of the workpiece surface and tool life [2]. The quick and precise obtaining of results with the use of optical measuring devices allows you to supervise the geometry of the cutting tool both during the manufacturing process and after the working period.

Currently, there are many devices for non-contact spatial measurements on the market. They are characterized by diversified technical parameters and destiny. With some optical measuring systems, it is not possible to obtain three dimensional geometries of cutting blades with high accuracy and repeatability. A particularly difficult task is to measure the side edges of the cutting tool's edge and the angles between side surfaces smaller than $30^{\circ}$. Therefore, an effective method of selecting an optical monitoring system for the production of cutting tools and assessing the state of their wear is sought.

* Dr hab. inż. Jan Burek prof. PRz (jburek@prz.edu.pl), mgr inż. Barbara Jamuła (b.jamula@prz.edu.pl) - Katedra Technik Wytwarzania i Automatyzacji, Wydział Budowy Maszyn i Lotnictwa Politechniki Rzeszowskiej

\section{Measuring systems}

Two complete solutions for tool geometry measurements were used in the research: the Comet L $3 D 2$ blue laser scanner from Zeiss (detector resolution $2448 \times 2050$ points, measuring field $74 \times 62 \times 45 \mathrm{~mm}$ ) and the Infinite Focus G4 focal point microscope from Alicona (2.5× magnification, resolution $1624 \times 1232$ points, field of view $5.7 \times 4.3 \mathrm{~mm}$ ).

The Comet L $\exists D 2$ scanner is characterized by the layout of one camera and one projector, thanks to which it is easy to acquire data about the measured object. Innovative technology in the scanner, ensuring high intensity and fast light sensor, guarantees the flexibility of performing measurements in various places. Obtaining information about the location and shape of the measured object using structural light scanners is based on the trigonometric triangulation principle. Triangulation consists in calculating the intersection of the plane and the ray in space (fig. 1).

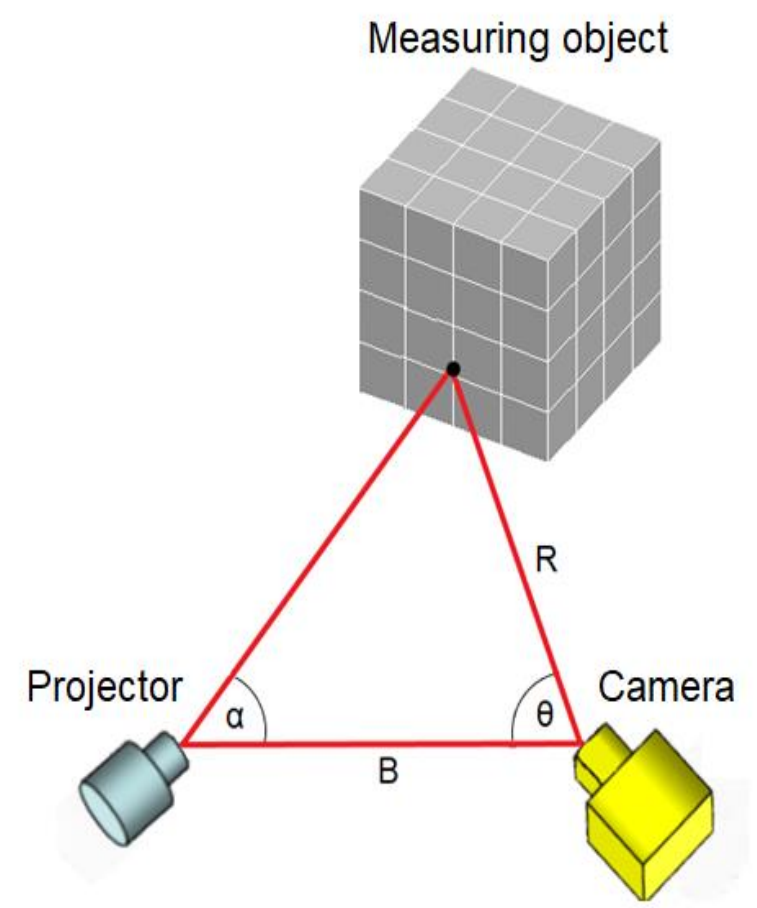

Fig. 1. Scheme of the triangulation method used in optical systems used to obtain 3D images 
Reconstruction of the geometric shape of the whole surface of the scanned element is possible due to the projection of a characteristic pattern of this surface with a small number of acquisitions and without the necessity of relative movement of the device and the measuring object.

The distance between the camera and the surface of the measured object can be determined by:

$$
R=B \cdot \frac{\sin \theta}{\sin (\alpha+\theta)}
$$

where: $R$ - distance between the camera and the surface of the object being measured; $B$ - distance between the camera and the projector; $\alpha$ - angle between the beam of light emitted by the projector and the section connecting the projector with the camera, $\Theta$ - angle between the beam of light reaching the camera and the section connecting the projector with the camera.

Simple calibration of the device in the place of measurements allows you to quickly adjust the measurement field by changing lenses. The stable tripod on which the measuring head is mounted, equipped with a projector and camera, gives the possibility of adjusting the height and distance to the object to be measured.

An important element in this type of scanners is the rotary table, on which the object to be measured is mounted and automatically set. Three-dimensional images of mapped surfaces are obtained using advanced Zeiss colin3D software. This program both collects and processes data received on the basis of measurements, and enables comparison of measurements with theoretical models and generates reports.

The plane created by the patterns of structural light beams projected by the projector and projected onto the measured surface intersects with the ray extending from the center of the pixel of the camera matrix. Based on the position of the projector relative to the camera and the parameters of the lenses of these devices, equations of halfrays and planes corresponding to the points of the image can be reproduced. The result of a single measurement is a cloud of points, the number of which depends on the resolution of the camera.

Optical Infinite Focus system from Alicona is used for micro and macro measurements. A key element of this apparatus is precision optics with various lens systems that can be equipped with measuring lenses to perform measurements with different resolution.

The system uses independent and innovative techno logic of differential variation (fig. 2). It combines a small depth of field with Z-axis scanning (EN ISO 25178). The measuring object is illuminated with modulated white light. Coaxial lighting is achieved by directing the light from the optics and focusing them through the lens on the analyzed object (sample) with the help of a translucent mirror. After reaching the object, the light reflects from its surface in various directions, and then it is projected by means of precision optics on the digital sensor.

Due to the low focusing depth, only a small portion of the object has a sharp image (in the focus) and only this part of the image is used for further processing. Shape measurement is obtained by vertical scanning of the surface, i.e. changing the distance between the lens and the detector, and supplementing areas where previously no focus was achieved. Each area of the analyzed object has an image in the focus in one vertical position of the microscope. Data from individual images are processed into a three-dimensional view. It is possible to obtain images at different resolution values laterally or vertically, depending on the selected lens.

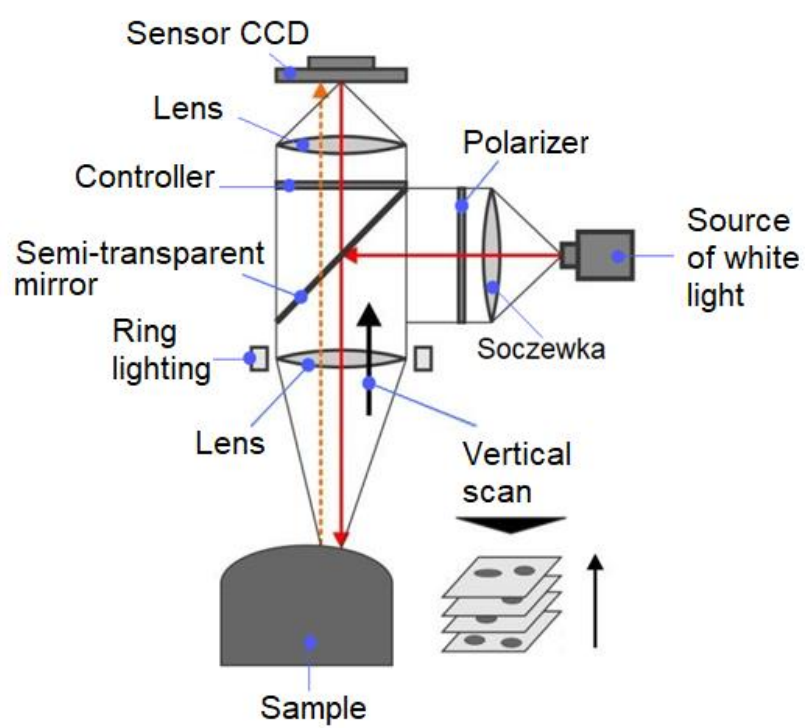

Fig. 2. Scheme of the system for measurement by focal differential - focus variation

\section{Measurement of blade geometry}

A four-headed monolithic tungsten carbide milling cutter was used for the tests. This milling cutter was placed in a rotating unit at an angle of $45^{\circ}$ for the needs of the Infinite Focus optical system. The surface was scanned using a $2.5 \times$ magnification lens. In addition, to obtain results without large differences in brightness, ring light with a polarizing disk was installed. Digital models were subjected to additional data processing. Measurement noise created as a result of external factors was removed different. a)

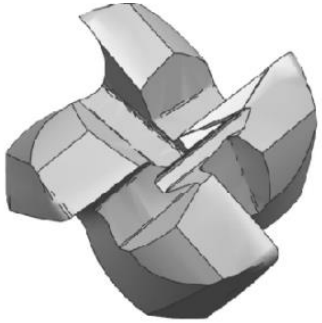

b)

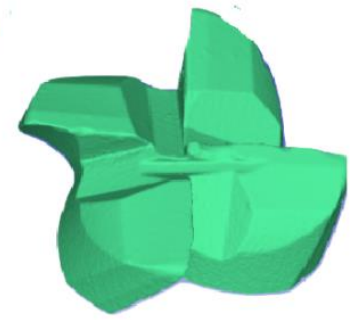

c)

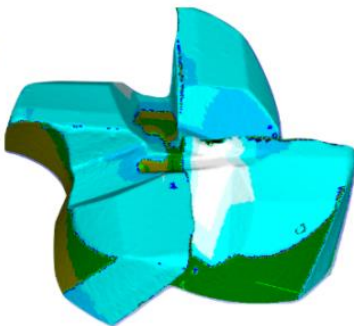

d)

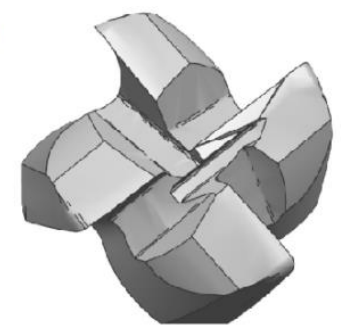

e)

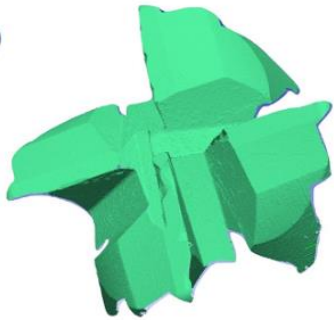

f)

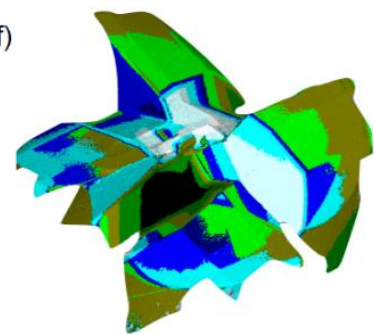

Fig. 3. Three-dimensional surfaces of the cutter's edges: a), d nominal surfaces, b) surfaces obtained using the ZEISS Comet LヨD 2 scanner, c) deviation map obtained by comparing the surface $a$ and $b, e)$ surfaces obtained with the use of a microscope Infinite Focus G4 by Alicona, f) displacement map obtained by comparing surfaces $d$ and $e$ 
With the Comet L $\exists D 2$ optical system, three-dimensional mapped surfaces were obtained in such a way that a milling cutter was mounted on the rotary table and the geometry of its blades was measured using a lens with a field of view of $118 \times 98 \times 60 \mathrm{~mm}^{3}$. Subsequent measurements were made with a lens with a smaller field of view $-74 \times 62 \times 45 \mathrm{~mm}^{3}$. Recent studies have been made with a lens with the same field of view, but because the cutter had shiny surfaces, it was covered with a powder that reduces reflection.

Three-dimensional cutter surfaces obtained using both optical measuring systems allowed to evaluate the quality of the mapping geometry of the cutting tool blades.

To determine the accuracy of measurements, surfaces obtained on the basis of measurements were applied to non-nominal surfaces of the designed cutter. The process of verification of the accuracy of $3 D$ surface mapping was carried out using the Focus Inspection software. The adaptation of nominal surfaces obtained at the CAD design stage and the reference surface created on the basis of measurements using a blue structural light scanner and a focal focus microscope were carried out with the best fit method with an accuracy of $0.001 \mathrm{~mm}$ (fig. 3).

\section{Test results}

The accuracy of the cutter geometry mapping geometry was defined as the value of the difference between the refinement value (designed in the CAD system) and obtained as a result of measurements with optical devices. An example of the result of the combination of the face faces of the cutter with the measured surfaces is shown in fig. 4 and fig. 5 .

\section{TABLE. Measurements}

TABLE. Measurements
\begin{tabular}{|l|c|c|}
\hline Device & $\begin{array}{c}\text { Average deviation } \\
\mathrm{mm}\end{array}$ & $\begin{array}{c}\text { Standard } \\
\text { deviation } \\
\mathrm{mm}\end{array}$ \\
\hline Alicona Infinite Focus G4 & 0.011 & 0.197 \\
\hline Zeiss Comet LヨD 2 & 0.016 & 0.092 \\
\hline
\end{tabular}
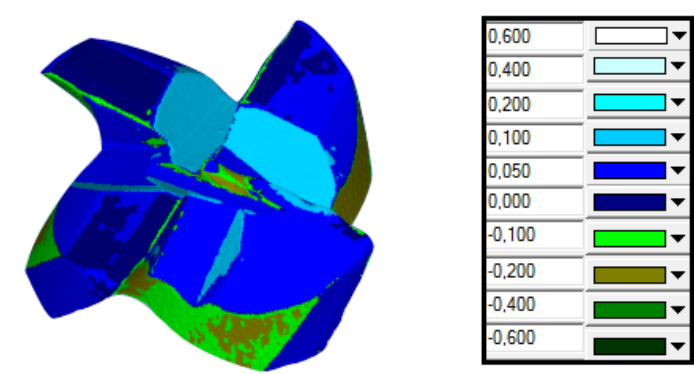

Fig. 4. Displacement maps (in $\mathrm{mm}$ ) for geometry measurement of the mandolin cutter blades using the Zeiss Comet L $\exists D 2$ scanner

Based on the analysis of the results obtained with the Infinite Focus G4 system from Alicona, it was noticed that the biggest deviations occurred in the grooves on the face of the milling cutter, and the smallest - on the main flank surface. The deviation values at the cutting edges were a maximum of $-0.1 \mathrm{~mm}$. Some fragments of the secondary flank were not re-marked.

In turn, when considering the images obtained with the Comet L JD 2 optical measuring system from Zeiss, it was noticed that after using a lens with a larger field of view, cutter surfaces, such as the auxiliary relief surface and the rake surface, are not reproduced. The smallest deviations were obtained using a lens with a field of view of $74 \times 62 \times$ $45 \mathrm{~mm}^{3}$. In the case of images with this field of view, it was found that the largest deviations were obtained at the cutting edges and on the rake face. The values on the rake surfaces are up to $0.2 \mathrm{~mm}$. The smallest deviations were obtained on the secondary and main flank - maximum $0.005 \mathrm{~mm}$.
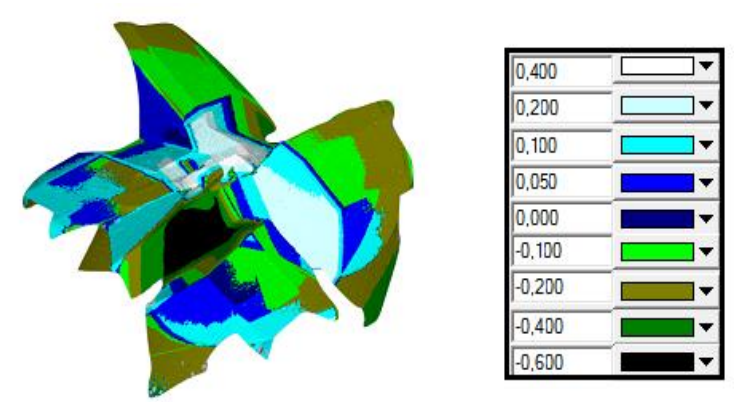

Fig. 5. Displacement maps (in $\mathrm{mm}$ ) for measurement of the geometry of the spindle nose with an Infinite Focus G4 microscope by Alicona

\section{Conclusions}

The main advantages of the structured light projection, using the Comet L $\exists D 2$ system, are the quality of digitalization and the time of data processing. In addition, in this type of system, you can analyze both the geometry of the blades and the entire geometry of the cutting tool, especially its working part. However, in the case of surfaces on the cutting tool blades, an exact representation of the rake face and the cutting edges becomes problematic.

The technique of focal differentiation, used in the optical measurement system Inifnite Focus by Alicona, allows measurements on the micro and macro scale. Re-forming the steep surfaces of the cutting tool is not the slightest problem for this type of optical system. The surfaces of cutting tools with strong reflections can be measured by using a polarizer. In the case of an optical system using structural light technique, this is impossible, which results in coating the measured object with matting powder. That's why the Infinite Focus measuring system has found a wide application in the tool industry, including to assess the wear of the cutting tool blades.

\section{REFERENCES}

1. Chen F., Brown G.M., Song M. „Overview of three-dimensional shape measurement using optical methods". Optical Engineering. 39, 1 (2000): pp. 10.

2. Danzl R., Helmli F. „Geometry and wear measurement of cutting tools". Int. Conf. on High Perf. Cutting. 1 (2008): pp. 111-118.

3. Huang Y, Qian X. „A dynamic sensing-and-modeling approach to three-dimensional point- and area-sensor integration". J.Manuf.Sci.Eng. 129, 3 (2006): pp. 623-635.

4. Martínez S., Cuesta E., Barreiro J., Alvarez B. „Methodology for comparison of laser digitizing versus contact systems in dimensional control". Optics and Lasers in Engineering. 48, 12 (grudzień 2010): pp. 1238-1246.

5. Neuschaefer-Rube U., Wendt K., Ehrig W. „Optische Sensoren für die Koordinatenmesstechnik - Prinzipien und Prüfung”. PTBMitteilungen. 117 (2007): pp. 380-389.

6. Sładek J., Sitnik R., Kupiec M. „Ocena dokładności metody optycznej: koncepcja metody hybrydowej w pomiarach współrzędnościowych". Zeszyty Naukowe Politechniki Poznańskiej. Budowa Maszyn i Zarządzanie Produkcją. 1 (2004): pp. 345-352.

Translation of scientific articles, their computer composition and publishing them on the website www.mechanik.media.pl by original articles in Polish is a task financed from the funds of the Ministry of Science and Higher Education designated for dissemination of science.

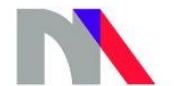
and Higher Education Republic of Poland 